\title{
QUEM É O LEITOR DE TEXTOS JURÍDICOS? UMA EXPLORAÇÃO SOBRE OS OMBROS DE RICARDO PIGLIA
}

\author{
Túlio de MEdeiros JALES ${ }^{1}$
}

\begin{abstract}
RESUMO: Utilizando-se da descrição do leitor de literatura fornecida pelo novelista e crítico literário argentino Ricardo Piglia em sua obra El ultimo Lector, o trabalho, em formato de ensaio, busca identificar quais seriam os predicados do leitor de textos jurídicos, verificando se tais características se assemelham ou não àquelas do leitor "pigliano".
\end{abstract}

Palavras-chave: leitor jurídico; Ricardo Piglia; El ultimo lector.

\section{DO TRAÇADO DAS PERGUNTAS}

Quem é, afinal, o leitor de textos jurídicos? Possui tal leitor uma predicação diferenciada daquela atribuída aos leitores de romances? A resposta a essa pergunta será urdida a partir de um exercício de comparação que buscará proporcionar um perfil, ou pelo menos uma silhueta própria, do leitor de obras jurídicas. Serão tomadas como parâmetro a descrição e as reflexões que o romancista e crítico literário argentino Ricardo Piglia tece sobre a figura do leitor enquanto personagem particularmente tratado na literatura para, na sequência, investigarmos se o leitor jurídico assemelha-se ou não a esse universal leitor literário. A caracterização do leitor pigliano fornece uma âncora objetiva ao ensaio, impedindo que as reflexões ensaísticas por mim empregadas para explorar a imagem do "leitor-jurídico" façam naufragar as intenções do texto. O caminho que se segue, pois, é o de questionar a possibilidade de uma particularização. Do leitor universal, representado pelo leitor de literatura,

Doutorando em Direito do Estado pela Universidade de São Paulo (USP). Mestre em Constituição e Garantias de Direito pela Universidade Federal do Rio Grande do Norte (UFRN). São Paulo, SP, Brasil. CV Lattes: http://lattes.cnpq.br/2603672957639753. Email: tulio_jales@hotmail.com 
ao leitor jurídico. Se o Ramón Bonavena de Borges e Bioy Casares, ante as dificuldades hercúleas impostas pela criacionice literária, viu-se obrigado a acolher como objeto de sua produção a descrição do limitado canto da mesa de pinho sobre a qual trabalhava, o autor que vos escreve se vê igualmente moldado por uma formação que é, em termos literários, anêmica, e em termos jurídicos, bulímica (Bioy Casares; Borges, 2014, p. 41). Ao tempo que esse fundo formativo pessoal me fecha as portas para um exercício de desacordo ou complemento à descrição de Ricardo Piglia sobre o leitor de romances, abre-me a possibilidade de investigar, com o mínimo de segurança, se aquela descrição se aplica aos tipos de leitores com que mais convivo.

\section{O LEITOR PIGLIANO}

No prólogo de El último Lector, seu conjunto de ensaios sobre a personalidade do leitor na literatura universal, Piglia nos fornece uma metáfora que se converte em chave para o entendimento de suas cogitações. Nela, o narrador visita Russel, um fotógrafo que construiu em sua casa no bairro de Flores uma réplica em tamanho reduzido da cidade de Buenos Aires. O jogo metafórico se dá na medida em que Russel acredita que sua criação não seria uma simples representação da capital argentina; invertendo a relação de representação, é o destino da cidade portenha que está diretamente dependente do que ocorre na invenção do fotógrafo. $\mathrm{O}$ canal a permitir a viragem representacional entre a cidade e a réplica é o próprio observador da invencionice: "vi la ciudad y o que vi era más real que la realidade, mas indefinido y más puro" (Piglia, 2014, p. 15). A experiência de impacto que assalta o observador da cidade ficcional permite a esse sujeito um novo olhar sobre a realidade, uma nova forma de enxergar "a real" Buenos Aires. A fantasia, indica Piglia, é capaz de mais profundamente afetar seus interlocutores do que a própria realidade crua. A máquina de Russel é a imagem de Piglia para a literatura, enquanto seus observadores correspondem aos leitores. A ficção, assim, transmuta-se na convencionada realidade, e o que apenas imaginamos já passa a existir pela simples razão de imaginarmos.

As pontas imagéticas deixadas pelo prólogo sobre o perfil do leitor desenvolvem-se ao longo do livro em seis ensaios. O método movido por 
Piglia nesses escritos é pinçar e comentar casos específicos nos quais escritores tenham, direta ou indiretamente, debruçando-se sobre a figura nem sempre tão passiva - daquele que lê. $O$ trabalho é apresentado como dificultoso pois, por sua natureza, o leitor tende a ser invisibilizado na narrativa literária. $\mathrm{O}$ traçado do nosso texto permite que condensemos as digressões realizadas por Piglia nos seis ensaios, a fim de formarmos uma composição una de seu leitor. Essa composição unitária não quer significar, no entanto, a montagem de um personagem coerente e sem paradoxos. $\mathrm{O}$ leitor de Piglia não se revela como uma cidade planejada, mas, sim, personaliza colorações que se apresentam em tensão. "Leitor radical", "leitor moderno", "leitor contemporâneo" e "leitor perfeito", são algumas das imagens forjadas por Piglia para empreender sua proposta descritiva e analítica. Se a unidade de sentido do que se lê é algo ilusório, o próprio perfil do leitor também o é.

Começando essa caracterização pelos seus antípodas, temos que um "leitor radical" vê na leitura uma forma de vida. Essa dimensão limítrofe é a mesma adiantada no prefácio, sendo o leitor alocado como articulador entre o real e o imaginário. Essa maneira de vivência do leitor é, assim, uma eterna comunicação, não entre ficção e realidade, mas entre duas dimensões do real: a realidade produzida pela leitura e a realidade ordinária. Será o leitor, pois, aquele capaz de ter sua vida modificada pela leitura. Um exemplo concreto dessa figura nos é dado quando o ensaísta argentino discorre sobre a mudança que a máquina de escrever ocasionou à vida das mulheres ao oportunizar o exercício da datilografia - ofício simbolizador, a um só tempo, da copista e da leitora. As datilógrafas são, antes de tudo, leitoras que tiveram a materialidade de suas vidas alteradas pela possibilidade de ler.

A dualidade entre realidade literária e realidade ordinária, contudo, também traz riscos. Dois deles são explicitamente comentados. O bovarysmo, em referência à obra de Flaubert, seria a inclinação do leitor a incorporar a vida do personagem que lhe é apresentado na narrativa literária. O leitor mimetizaria os passados dos personagens com quem se identificasse. A vida exótica ou alternativa dos personagens induziria leitores a abdicarem de sua existência bolorenta para buscar a si próprios nas inspirações das vidas literárias. O segundo é o quixotismo. Fundador do 
romance moderno, o herói de Cervantes é o idealista enclausurado na realidade. Sua alucinada realidade imaginativa é tão absurda que não chega a poder interagir com a dimensão ordinária do real. O quixotismo seria a doença do leitor impotente; a hipertrofia da realidade literária sobre a realidade ordinária. Em uma hipótese suscitada em seus ensaios, colhida a partir da tese do historiador francês Roger Chartier, o ensaísta argentino concede espaço à suspeita de que o romance, enquanto gênero, foi capaz de redefinir a forma de leitura de todos os demais gêneros literários. Com o romance, não se lê mais para contestar os signos ou decifrar significados, mas sim confia-se nos signos já dispostos na leitura. Em outras palavras, com o romance passamos a ler para crer. Piglia parece querer dizer ao seu leitor que o radicalismo na leitura também deve ser evitado. A existência de duas dimensões da mesma realidade não implica a inferência de que não haja diferença entre elas.

As realidades literária e ordinária, no entanto, modificam-se. Esse vértice é abordado por Piglia ao pincelar as transformações do leitor através dos séculos. De Shakespeare a Borges, passando por Kafka e Poe, o leitor moderno e o leitor contemporâneo enfrentam dilemas assimétricos. Para nosso teórico argentino, Hamlet inaugura o homem moderno ao fundar o leitor como símbolo da consciência moderna. A racionalidade hamletiana se forja na leitura. É um período de estudos em Wittenberg que permite ao príncipe da Dinamarca a emergência de uma individualidade capaz de contestar as imposições que variáveis desconhecidas (destino, oráculo, sombras, deuses) impunham sobre a sua humanidade. Cronologicamente mais a frente, o detetive do gênero policial surge como variação desse homem racional, um agente engenhoso capaz de desvelar crimes obscuros no cenário hostil das metrópoles industrializadas. Na primeira cena de Assassinatos na rua Morgue, de Edgar Allan Poe, Auguste Dupin está justamente em uma livraria e é através da leitura que se dará a resolução dos crimes da história. O leitor é, para Piglia, um dos mitos de origem da modernidade humana.

Se essa imagem fundada em Shakespeare e avançada por Poe caracterizaria o leitor moderno como um ser socialmente deslocado, disposto a perturbar a naturalidade do cotidiano, o leitor contemporâneo, ao seu turno, ver-se-á perturbado e perdido ante a inundação de signos a 
sua volta. Na contemporaneidade, parecemos transitar do leitor desafiante para o leitor desafiado pelos próprios signos a serem lidos e decifrados. Citando Borges, Piglia aponta que, em um universo onde tudo está escrito, só nos resta reler, ou seja, ler de outra forma. O que está escrito não depende só de quem escreveu, mas também de quem lê. O leitor é desafiado a encontrar conexões ainda não realizadas entre os materiais já escritos. Esse desafio, paradoxalmente, parece ser consumado na escritura. Aqui, Piglia impõe a necessária correlação entre o leitor e o escritor. Porque lemos, escrevemos. A forma como escrevemos modifica a maneira que lemos, tanto quanto a forma com que lemos altera o modo como escrevemos. Escreve-se para fazer conexões, entrelaçar as leituras, forjar significados ainda latentes, mas não expressados. Conexões que a realidade vivida sem a reflexão escrita não permite divisar.

Os desafios impostos pela leitura ao leitor o obrigarão a procurar caminhos alternativos. Ricardo Piglia identificará aí a alma do movimento literário e social da beat generation. O leitor tenta se afastar do senso comum, diferenciar-se por meio de um "desalinho deliberado", ou seja, tecer um caminho alternativo passível de relevar a sua identidade literária em meio a um mar de leitura disponível. Ernesto Guevara de la Serna, o Che, exemplifica o leitor modelo desse estágio da arte. A carga imagética de seu célebre compatriota enseja a discussão sobre as relações entre leitura, intelectualidade e política. Guevara aliou a sua personalidade de leitor de leituras alternativas à sua capacidade de tecer um caminho político original. Como menciona Piglia, ninguém se torna guerrilheiro lendo Marx. Leitura e vida prática são, em verdade, antagonizadas, como se o leitor impedisse o nascimento do ator político, e vice-versa. Guevara representa o rompimento dessa tensão. Para ele, trata-se de viver o que se lê e escrever o que se vive. O político compartilha com o leitor a busca por uma nova realidade. Duas maneiras de promover a feitura do imaginado a partir da concretude presente.

No último dos ensaios presente no livro, a discussão sobre os problemas de construção e de interpretação nas obras de James Joyce leva Piglia a sugerir o que seria o modelo de leitura do leitor perfeito. A perfeição estaria na capacidade de o leitor resolver os significados cifrados que os autores deixam na obra, requerendo de quem as lê uma atenção minuciosa 
aos detalhes e uma capacidade de compreensão quase intuitiva em relação à intenção do escritor. O leitor perfeito está apto a alcançar a linguagem privada do autor, encontrando tesouros de significado que o escritor esconde em meio ao texto. É ele, em verdade, que comprova não haver linguagem privada, somente existindo a linguagem em contato com o outro. O escritor seria incapaz de, unicamente através de seu ator produtivo, emprestar significação plena ao texto. É o leitor quem, sabendo mais que o autor, é capaz de decifrar todos os sentidos da obra. Não há forma melhor de ler os próprios textos que não seja aquela realizada por meio dos olhos dos outros.

Discussão entre realidade e ficção, bem como os perigos dessa dualização da realidade; o leitor desafiante da vida ordinária e o leitor assomado pela pluralidade de significações da contemporaneidade; o leitor inimigo do senso comum e engajado em um caminho alternativo para além do ficcional, alcançando o político; o leitor perfeito, apto à hercúlea tarefa de interpretar o que não quer ser interpretado: com essas digressões, Piglia nos oferece um panorama relevante da figura do leitor no meio literário. A partir deste ponto o nosso ensaio pretenderá discutir em que medida essa representação do leitor de literatura se aplica àquele que lê textos jurídicos. Quando um jurista toma um texto jurídico para ler, seriam suas intenções e a natureza da interação que ele estabelece as mesmas presentes no leitor literário?

\section{PREDICANDO OS LEITORES JURÍDICOS}

Se a literatura não existe sem o leitor, o fenômeno jurídico viveu por séculos sem que os leitores ocupassem um protagonismo em sua trajetória. $\mathrm{O}$ direito era um fenômeno constituído por falantes e ouvintes e diferenciado por meio de rituais específicos em que essas relações orais se estabeleciam (Pádua, 2011, p. 115). Do fato da oralidade deter predomínio não se segue a inexistência de ordenações escritas. Tabulações jurídicas são conhecidas desde as civilizações pré-romanas. O significado desses suportes escritos, contudo, diferia do hoje existente. Marcar direito em pedras ou papéis era um ato de dimensão eminentemente evidenciária, não constitutiva. Registrava-se o que já tinha sua existência constituída a partir de um ato de fala (Tiersma, 2000, p. 110). Com a prevalência da oralidade 
sobre a escritura na profusão da realidade jurídica, encontramos a predominância do ouvinte sobre o leitor, do auditório sobre a biblioteca. $\mathrm{O}$ direito se aprendia e se exercia oralmente. Ao contrário da interação solitária entre a máquina de Russel e seu observador, ou seja, do leitor com o livro, o fenômeno jurídico tem sua gênese como construção coletiva, por meio das assembleias de discussão comunitária.

Nesse ambiente de escassez da palavra lida, restava encontrar os leitores nos próprios oradores. Cícero escrevia seus discursos não para serem lidos, mas para serem ouvidos do alto da Tribuna e discutidos pelas vozes do Parlamento. O legislador, personagem com a paternal responsabilidade de fazer nascer o direito, não é apenas aquele que escreve as leis, é, antes, o parlamentar, aquele que conversa, que discursa a legislação. O discursar difere do escrever. Quando a palavra ouvida sobrepuja a escrita, importa somente ser leitor de si. Em termos jurídicos, Cícero é o único leitor de si mesmo, ao seguir com os olhos o que escrevera para o ofício do púlpito. Ao voltarmos à obra que inaugura o romance moderno, constatamos que Cervantes já possibilita visualizar a tensão entre oralidade e escritura. Enquanto Don Quixote é aquele que lê, Sancho quase se gaba por não poder ler. Oralidade e escrita se unem, no entanto, ao simbolizarem matizes diferentes do fenômeno linguístico. $\mathrm{O}$ fato de $\mathrm{o}$ direito estar desabrigado da palavra escrita não significa, assim, a ausência de uma linguagem. A oralidade era a linguagem do direito.

A prevalência da oralidade passou ao largo de ser uma escolha para o mundo jurídico. Foi, antes, uma necessidade. Os problemas causados pela ausência de uma cristalização do oral são simbolizados pelo brocardo latino - e, atualmente, presidencial - "Verba volant, scripta manent". As palavras voam, os escritos permanecem, e, com a ascensão de um modelo de produção econômica em que a limitação do arbítrio, a segurança e a previsibilidade nas relações jurídicas deveriam ser os bens mais resguardados, o ideal seria um cenário com menos ouvintes e mais leitores. Dos Discursos passamos às Declarações de Direito. Dos oradores, aos intérpretes. Por mais que o produto jurídico tivesse fonte divina ou natural, era necessário escrevê-lo para lhe dotar de leitores e, por consequência, de autoridade. Os leitores jurídicos, mormente aqueles leitores abraçados pelo ente estatal normogênico, passam a ser fiadores da segurança que a escrita 
representava, portadores da verdade estatal-jurídica. A realidade jurídica é constituída pelos olhos dos leitores jurídicos; e o exercício de força, estranho à determinadas leituras oficiais da legislação, ganha status de ilegal. O direito positivado, escrito, pretende ser a totalização da realidade jurídica estável. É certo que há vida social fora do direito e que o jurídico nem tudo regula, mas, nos loci em que a marca jurídica normativa se encontrar, só haveria a realidade dos textos jurídicos que os leitores oficiais deveriam estar aptos a seguir e que os leitores cidadãos, por seu turno, deveriam estar dispostos a cumprir.

A pretensão de verdade da literatura jurídica enquanto fenômeno documental esbarrará, contudo, na pretensão do próprio leitor jurídico. É essencial notarmos o tensionamento ontológico entre as pretensões dos textos e do leitor no habitat legal. Enquanto os textos normativos pretendem emprestar limites e fronteiras à construção de sentidos na realidade jurídica, o leitor jurídico instrumentalizará o escrito ao sabor da ficção interpretativa que ele pretende ver prevalecer em um caso legal. Se o leitor puro de literatura será aquele que, crendo no escrito, terá sua vida ordinária modificada pela realidade ficcional com a qual entra em contato, o leitor de textos jurídicos será quem forçará a difusão da aplicação da sua realidade interpretativa da norma. A esfera legal parece levar aos antípodas práticos da indicação de Piglia de que a constituição do texto depende, na mesma proporção, de quem o interpreta e de quem o escreveu.

A diferença entre o leitor novelesco e o leitor jurídico parece ser que o primeiro se consuma ao ser transformado pelo texto, ao ter seu infinito particular vivificado pela ficção, enquanto o segundo não se completa até fazer com que a sua ficcional intepretação do texto jurídico seja transmutada em realidade, para além de si próprio. Ambos pretendem promover a afetação da realidade ordinária pela realidade ficcional de suas interpretações, ou seja, garantir uma expressão prática da realidade não literária. A diferença, no entanto, é divisada na amplitude dessa influência do ficcional sobre o real.

Enquanto o leitor pigliano parece satisfeito com a revolução que o romance provoca em si próprio, o leitor jurídico necessita fazer com que a realidade de sua ficção assome terceiros, sob pena dessa realidade ficcional tornar-se real, mas não se fazer jurídica. Obrigar outros, para além de si 
próprio, a embarcar em sua leitura interpretativa, é este o desafio do leitor jurídico. Quem lê textos jurídicos está necessariamente envolvido em uma tarefa política e social, numa realidade que desborda seu próprio umbigo e que variará a intenção da transformação coletiva, a depender da função social jurídica que este leitor estiver a cumprir. Ao passo que a relação de persuasão na leitura pigliana se opera somente entre o livro e seu leitor, o leitor jurídico está fadado ao fracasso, se não conseguir impor sua realidade ficcional à realidade do direito estatal, isto é, fazer com que sua interpretação seja acolhida pelo Estado e, por meio desse Estado, torne-se cogente a terceiros. $\mathrm{O}$ advogado que vai de encontro a uma interpretação prevalecente em determinado Tribunal está simplesmente a afirmar que é a sua leitura dos textos jurídicos, a sua ficção jurídica própria, que detém a verdade sobre o texto. A disputa jurídica é, sobretudo, uma disputa entre leitores que precisam convencer outros leitores da correção de suas interpretações;

Nessa disputa, apresentar-se como leitor é uma das marcas mais distintivas da comunicação jurídica. As citações, mobilizadas nos mais diversos matizes, desde artigos acadêmicos a pedidos de habeas corpus, são expressões da autoridade que a posição de leitor encerra no plano do conflito jurídico. $\mathrm{O}$ argumento é bom quando pode ser confirmado por meio do aval de outros leitores. Referenciar é sinônimo de compartilhar a mesma forma de ler o texto. Textos acadêmicos pouco referenciados, ou seja, deficitários em abrigar ecos de leituras, possuem uma visual falha argumentativa. Peças judiciais nas quais se ausentam referências à realidade de leitura predominante dos tribunais estatais já denotam quão frágil é a probabilidade de vitória. A incorporação da leitura pode chegar ao nível em que o escritor de peças ou estudos jurídicos parece querer esconder-se totalmente por detrás da autoridade do escrito por suas referências. Em peças judiciais, a estratégia recomendável pode ser que você demonstre ser muito mais um leitor de argumentos de autoridade do que propriamente um escritor capaz de atribuir autoridade a algum argumento próprio. Caso demonstre ter lido algum excerto do indivíduo ou instituição ao qual o documento se dirige, melhor ainda. Como nos tempos de Cícero, mas por outras razões, os leitores jurídicos permanecem sendo leitores de si mesmos. 
A diferenciação entre a imagem do leitor e a imagem do intelectual parece confundir a cabeça dos leitores e, por consequência, dos escritores jurídicos. Em uma obra literária, a estética amolda-se ao objetivo transformador que a obra quer causar. Quando Julio Cortázar decide brincar com o fazer literário e convida o leitor a ler o seu $O$ jogo da amarelinha por percursos diferentes, ele está a sublinhar que o tracejo, a ordem em que se ler os capítulos de um romance, pode fazer com que o texto seja interpretado de formas diferentes, mas ainda assim fazer sentido. O "tabuleiro de leitura" de Cortázar não trata de dificultar a vida do leitor, mas, sim, de orientá-la para uma experiência estética nova, sem a qual a obra não cumpriria sua função ${ }^{2}$. É dizer, a estética da obra faz parte da própria substância funcional do escrito.

No texto jurídico, o objetivo de transformar a interpretação do leitor da norma em interpretação oficial é muitas vezes embaçado por demonstrações de estilismo vocabular e riqueza cultural inapropriadas à tarefa. Artifícios estéticos de rebuscamento linguístico, ao invés de servirem à finalidade da obra - o convencimento do leitor -, acabam distanciando quem lê do argumento que se pretende desenvolver. Caso estejamos lidando com atores que produzem textos voltados não só apenas para o microcosmo jurídico, mas para toda a sociedade, o cuidado com o estilo redacional deve ser ainda mais incrementado. Nessas hipóteses, em que se inserem diretamente magistrados e oficiais do governo, não se trata apenas de convencer outros leitores jurídicos, mas, sim, de comunicar uma mensagem à sociedade em geral. Há uma responsabilidade de prezar pela inteligibilidade entre escritores e leitores, sendo o estilo redacional dessa tarefa tão importante quanto seu conteúdo (Sachs, 2009, p. 270). Se o leitor perfeito de Piglia seria aquele capaz de interpretar as sutilezas e captar os pormenores da narrativa, o escritor jurídico não pode esperar de seu leitor a perfeição capaz de devaneios intelectualóides e buscar, na alma textual, o lugar em que estejam escondidos os argumentos sustentadores da ficção

Cortázar chega a escrever, pela pena de Morelli (escritor ficcional do romance $O$ jogo da amarelinha): "No que me toca, pergunto-me se alguma vez conseguirei fazer sentir que o único e verdadeiro personagem que me interessa é o leitor, na medida em que algo do que escrevo deveria contribuir para mudá-lo, para deslocá-lo, para chocá-lo, para aliená-lo" (Cortázar, 2014. p. 496-497). 
interpretativa. O leitor jurídico perfeito, do contrário, exige do seu escritor clareza literária de uma estética voltada para a finalidade específica do convencimento. Nada pode ser mais literário e prazeroso a um leitor jurídico do que um texto que não esconde suas verdades por trás de palavras e expressões disfuncionais.

O panorama do uso das citações e a doença do exibicionismo intelectual ocasionados pela necessidade premente de se mostrar um leitor enciclopédico implicam o não aprofundamento dos leitores nas obras que leem. A superficialidade dificilmente oportuniza a busca por conexões e relações entre materiais já escritos, tarefa que Piglia vê como chave para fazer o leitor contemporâneo se diferenciar. A leitura é encarada como instrumento para afirmação do que se pretende dizer já antes de se haver lido. O imperfeito leitor jurídico possui um argumento prévio à leitura que precisa ser reforçado e robustecido por outras leituras similares. A leitura, que para Piglia deveria ser a arte da escala, do distanciamento e da aproximação, ocorre ao leitor jurídico como artifício para, amealhando aquelas realidades que lhe são mais contíguas, fortalecer concepções que lhe são previamente necessárias. No domínio acadêmico, os trabalhos que conseguem se destacar são justamente aqueles que fazem o oposto, ou seja, que conseguem se aprofundar e refletir sobre obras, deixando que elas os afete e modifique. É necessário que leitores jurídicos se apresentem como leitores não apenas por meio de citações, e, sim, demonstrando conexões e conversações aprofundadas com os escritos que versem sobre seus temas de pesquisa e trabalho. Com o aprofundamento, as correlações se oportunizam, e a singularidade da experiência literária vem à superfície.

\section{LEITOR JURÍDICO: DE TRANSFORMADO PELO TEXTO A TRANSFORMADOR DO TEXTO}

Com o auxílio da liberdade própria do gênero ensaístico, as reflexões traçadas nas últimas linhas permitiram, além de uma descrição daquilo que acredito caracterizar o leitor jurídico, a incorporação de algumas recomendações normativas necessárias àqueles que se debruçam sobre um texto jurídico. Podemos defender que a natureza desse leitor é diferente daquela com que Piglia caracteriza o leitor de romances. Enquanto este último se constitui no momento em que é afetado pela obra, necessita o leitor jurídico ir além e convencer terceiros a embarcarem em sua 
interpretação da obra jurídica. Para além de ser transformado pelo texto, como o é o leitor de Piglia, o leitor jurídico precisa ser um transformador dos textos que lê. Nessa dimensão ontológica, o leitor jurídico parece estar fadado a ser sintetizado no personagem mal leitor, aquele que discorda da hermenêutica, que se apresenta como dissidente interpretativo. $\mathrm{O}$ fato de estar no embate jurídico indica, no mínimo, que sua leitura quase sempre estará equivocada à luz da leitura de alguém.

O leitor jurídico também não deve ser alguém que interprete mensagens cifradas ou sentidos implícitos. Ao contrário do leitor perfeito de Piglia, que construía o sentido do texto desvendando pormenores deixados pelo literato, o leitor jurídico é um amigo da clareza do argumento e das pretensões do seu interlocutor. Isso não é uma declaração de inferioridade do leitor jurídico, mas somente uma constatação acessória à própria finalidade de seu ato de leitura. Também não sucede daí que o leitor jurídico não complemente o sentido dos textos que lê. O seu papel transformador sugere justamente o contrário, mas essa tarefa transformativa deve ser assessorada por uma estética não ocultadora das verdades dos textos. Nesse ponto, como se vê, a descrição do leitor jurídico casa com a recomendação aos escritores jurídicos.

Não só distâncias existem entre os tipos de leitores. Visualizamos como a profundidade e alteridade com o texto são importantes para ambos. Os dois tipos de leitores devem deixar o texto falar a fim de fazer com que as associações e as conexões com seus conhecimentos prévios brotem mais facilmente. Essa forma de interação permite que o leitor jurídico deixe de ser apenas um repositório de citações e nasça como um leitor reflexivo acerca daquilo que se lê. Só conhecendo bem o objeto que tem em mãos poderá o jurista exercer seu traço característico de leitor, passando de um ser transformado pelas páginas que lê a alguém capaz de transformar a realidade do que foi lido.

\section{REFERÊNCIAS}

BIOY CASARES, Adolfo; BORGES, Jorge Luis. Crônicas de Bustos Domeqc: novos contos de Bustos Domeqc. São Paulo: Globo, 2014.

CORTÁZAR, Julio. O jogo da amarelinha. Rio de Janeiro: Civilização Brasileira, 2014. 
PÁDUA, João Pedro Chaves Valladares. Vale o que está escrito: considerações em torno da relação entre direito e escrita. Direito, Estado e Sociedade, n. 38, p. 112-132, jan/jun 2011.

PIGLIA, Ricardo. El ultimo lector. Buenos Aires: Debolsillo, 2014.

SACHS, Albie. The strange alchemy of life and Law. Oxford: Oxford University Press, 2009.

TIERSMA, Peter. Legal language. Chicago: University of Chicago, 2000

Idioma original: Português

Recebido: 07/02/17

Aceito: 11/04/17 